\title{
Synthesis and performance of a polymeric scale inhibitor for oilfield application
}

\author{
Heming Luo $\cdot$ Dejun Chen $\cdot$ Xiaoping Yang $\cdot$ \\ Xia Zhao $\cdot$ Huixia Feng $\cdot$ Mingyang $\mathbf{L i} \cdot$ \\ Junqiang Wang
}

Received: 12 September 2013/Accepted: 22 May 2014/Published online: 22 June 2014

(C) The Author(s) 2014. This article is published with open access at Springerlink.com

\begin{abstract}
A potential polymeric scale inhibitor used for oilfield was synthesized by solution polymerization. The static inhibition rate on calcium carbonate, calcium sulfate, barium sulfate, and strontium sulfate can reach up to more than $95 \%$. The inhibition performance of the polymer on calcium fluoride was also evaluated. Effects including test temperature, $\mathrm{NaCl}$ concentration, $\mathrm{pH}$ value, and evaluation time on the performance of the polymer were researched. Scanning electron microscopy and X-ray diffraction analyses were used to investigate the influence of the antiscalant on the scale crystal. The impact of carbon dioxide on the calcium carbonate crystal was also found. The inhibitor has a well-inhibition rate of more than $90 \%$ in the actual oilfield water samples.
\end{abstract}

Keywords Copolymer - Scale inhibitor - Calcium fluoride $\cdot$ Barium sulfate $\cdot$ Oilfield water

\section{Introduction}

Scale is often defined as the precipitation from aqueous solution with inorganic sediments and scale deposition is a

H. Luo $(\bowtie) \cdot$ D. Chen $\cdot$ X. Yang $\cdot$ X. Zhao $\cdot$ H. Feng

School of Petrochemical Engineering, Lanzhou University of Technology, Lanzhou 730050, Gansu, China

e-mail: luohm666@163.com; luohm@lut.cn

M. Li

Zhejiang Satellite Petrochemical Company, Jiaxing 314201, Zhejiang, China

J. Wang

Sinohydro Group No. 4 Engineering Bureau, Xining 810007, Qinghai, China problem commonly existing in different processes in oilfield productions, for instance, water injecting, oil extracting, gathering and transporting, warming treatment, demulsification, crude oil dehydration and desalting, etc., meanwhile, the scale is prone to be appeared on the down hole, oil well casing, oil pipelines and other production equipments (Liu et al. 2012; Dickson et al. 2011). The scale deposition products in oilfield are mainly consisted of calcium carbonate, calcium sulfate, barium sulfate and strontium sulfate, iron, silicon sediment and other insoluble solids (Senthilmurugan et al. 2011; Dickinson et al. 2012) and the production of scaling is often due to the changes of thermodynamics conditions or the fluids incompatibility. Scale precipitation could cause various damages including blockage of pipeline and equipment, energy leak, accelerate corrosion, and severe accidents, which will influence the safety of production and the economic benefit of petroleum industry (El-Said et al. 2009) and thus should be avoided to the most extent in the oilfield industry.

Adding chemical antiscalant (also called scale inhibitor) is an economical and simple effective route for the prevention of scaling (Dickson et al. 2011). Numerous polymeric scale inhibitors with good scale inhibition performance had been reported in literatures, of which maleic polymers are widely used as scale inhibitor. For instance, copolymer of maleic acid-ortho toluidine, maleic acid-acrylic acid and maleic acid-acrylamide was adopted as an inhibitor for calcium sulfate and calcium carbonate (Senthilmurugan et al. 2010), and exhibited a well-inhibition performance. Itaconic acid used as monomer to synthesize a polymeric inhibitor was also studied by Shakkthivel and Vasudevan (2007). Recently, hyperbranched polymer (Jensen and Kelland 2012), modified polymer (Guo et al. 2012) and quadripolymer (Zhang et al. 2007) used as inhibitor draw more and more attention from 
industry and academia. However, most of the detailed studies are focused on inhibitor performance for calcium carbonate and calcium sulfate, but barium sulfate and strontium sulfate in few literatures were studied simultaneously. Few literature reports on the calcium fluoride are also being found in oilfield and on other industrial equipments (Shen et al. 2013). Preliminary study of the inhibition performance of synthesized polymer on calcium fluoride was done in this work.

As many literatures reported, it is meaningful to study more suitable copolymers for the scale prevention in oilfield application. In this work, a copolymer scale inhibitor, including the group of carboxyl, hydroxyl, amide, sulfonic acid and ester, was synthesized and the inhibition performance on calcium carbonate, calcium sulfate, barium sulfate, strontium sulfate and calcium fluoride was evaluated. Furthermore, the scale inhibition performance of the polymer in the produced water from oilfield was also evaluated. Due to the fact that calcium carbonate is a very common deposition in the oilfield, and barium sulfate is one most difficult to be dealt with, effects including test temperature, $\mathrm{NaCl}$ concentration, $\mathrm{pH}$ value, and evaluation time on the inhibition performance of the as-prepared polymer were studied. By means of XRD and SEM, the influences caused by the synthesized copolymer on the crystal structure of calcium carbonate, strontium sulfate and barium sulfate were investigated. Particularly, the impact of carbon dioxide on the calcium carbonate crystal was found, which was not mentioned clearly in the existing literatures.

\section{Experimental work}

\section{Materials}

Maleic anhydride, acrylamide, and hydroxypropyl acrylate were of analytical grade. 2-acrylamido-2-methyl-1-propanesulfonic acid was of purity of $99 \%$. All the chemical reagents used for the solutions preparation were of analytical grade. Carbon dioxide was of purity of $99.9 \%$. The deionized water was used throughout the experiments.

\section{Synthesis of the copolymer}

The copolymer was synthesized in an aqueous medium through free-radical polymerization using ammonium persulfate as initiator in an air atmosphere according to the following optimizing procedure. Weighted $60.0 \mathrm{~g}$ of maleic anhydride was added into $50 \mathrm{~mL}$ of deionized water, heated to $55{ }^{\circ} \mathrm{C}$ and dissolved, then $50.0 \mathrm{~g}$ of sodium hydroxide in $150 \mathrm{~mL}$ of deionized water was dropwise added while continuous stirring. After that the solution was heated to $75^{\circ} \mathrm{C}$, then $150 \mathrm{~mL}$ of deionized water combined with $30.0 \mathrm{~g}$ of acrylamide, $20.0 \mathrm{~g}$ of 2-acrylamido-2-methyl-1-pro-panesulfonic acid and $15.0 \mathrm{~g}$ of hydroxypropyl acrylate was added dropwise accompanying with $18.2 \mathrm{~g}$ of ammonium persulfate aqueous solution (with $50 \mathrm{~mL}$ of deionized water) dropwise added at the same time in about $60 \mathrm{~min}$. Then the mixture was heated to $80{ }^{\circ} \mathrm{C}$ and maintained for $4 \mathrm{~h}$ with stirring. The $\mathrm{pH}$ value of the medium was adjusted to $7-8$ with sodium hydroxide solution after cooling to $45{ }^{\circ} \mathrm{C}$, and finally the polymeric scale inhibitor was synthesized.

\section{Characterization and thermal stability of copolymer}

The polymer was purified through precipitation using methanol for characterization. Then the polymer was dried in vacuum oven with a pressure of $0.07 \mathrm{MPa}$ at $70{ }^{\circ} \mathrm{C}$ for $16 \mathrm{~h}$. The structure of the as-dried polymer sample was confirmed by FT-IR (Fourier transform infrared spectrometer, USA Nicolet AVTAR 360). The thermal stability was studied via the thermo gravimetric analysis (Germany STA-6400) in nitrogen environment from room temperature to $600{ }^{\circ} \mathrm{C}$ at a ramping rate of $10^{\circ} \mathrm{C} / \mathrm{min}$.

\section{Evaluation of the inhibition efficiency}

Following the NACE Standard TM0374-2007 and Chinese Petroleum Industry Standard SY/T 5673-1993 procedures, the static evaluation test for qualifying scale inhibiting properties of the polymer was conducted. The solutions for evaluation of the scale inhibition performance of the polymer were prepared as shown in Table 1 . Solutions C and $\mathrm{D}$ for calcium carbonate deposition inhibition performance evaluation were saturated using $\mathrm{CO}_{2}$ at room temperature while the upper space of the test flask is 30-35 mL. In the first step, a certain quantity of scale

Table 1 Brines and evaluation condition for inhibition experiments

\begin{tabular}{|c|c|c|c|}
\hline $\begin{array}{l}\text { Scale } \\
\text { test }\end{array}$ & Brine & Concentration $(\mathrm{g} / \mathrm{L})$ & Condition \\
\hline \multirow[t]{2}{*}{$\mathrm{CaSO}_{4}$} & A & $\mathrm{NaCl}=7.50, \mathrm{CaCl}_{2} \cdot 2 \mathrm{H}_{2} \mathrm{O}=11.10$ & \multirow{2}{*}{$\begin{array}{c}70^{\circ} \mathrm{C} / \\
24 \mathrm{~h}\end{array}$} \\
\hline & $\mathrm{B}$ & $\mathrm{NaCl}=7.50, \mathrm{Na}_{2} \mathrm{SO}_{4}=10.66$ & \\
\hline \multirow[t]{2}{*}{$\mathrm{CaCO}_{3}$} & $\mathrm{C}$ & $\begin{array}{l}\mathrm{NaCl}=33.00, \mathrm{CaCl}_{2} \cdot 2 \mathrm{H}_{2} \mathrm{O}=12.15 \\
\mathrm{MgCl}_{2} \cdot 6 \mathrm{H}_{2} \mathrm{O}=3.68\end{array}$ & \multirow[t]{2}{*}{$\begin{array}{c}70{ }^{\circ} \mathrm{C} / \\
24 \mathrm{~h}\end{array}$} \\
\hline & $\mathrm{D}$ & $\begin{array}{l}\mathrm{NaCl}=33.00, \mathrm{NaHCO}_{3}=7.36 \\
\mathrm{Na}_{2} \mathrm{SO}_{4}=0.03\end{array}$ & \\
\hline \multirow[t]{2}{*}{$\mathrm{BaSO}_{4}$} & $\mathrm{E}$ & $\mathrm{NaCl}=7.50, \mathrm{BaCl}_{2} \cdot 2 \mathrm{H}_{2} \mathrm{O}=0.66$ & \multirow{2}{*}{$\begin{array}{c}70^{\circ} \mathrm{C} / \\
16 \mathrm{~h}\end{array}$} \\
\hline & $\mathrm{F}$ & $\mathrm{NaCl}=7.50, \mathrm{Na}_{2} \mathrm{SO}_{4}=0.80$ & \\
\hline \multirow[t]{2}{*}{$\mathrm{SrSO}_{4}$} & G & $\mathrm{NaCl}=7.50, \mathrm{SrCl}_{2} \cdot 6 \mathrm{H}_{2} \mathrm{O}=8.16$ & \multirow{2}{*}{$\begin{array}{c}70^{\circ} \mathrm{C} / \\
16 \mathrm{~h}\end{array}$} \\
\hline & $\mathrm{H}$ & $\mathrm{NaCl}=7.50, \mathrm{Na}_{2} \mathrm{SO}_{4}=7.31$ & \\
\hline \multirow[t]{2}{*}{$\mathrm{CaF}_{2}$} & I & $\mathrm{NaCl}=2.0, \mathrm{CaCl}_{2}=2.22$ & \multirow{2}{*}{$\begin{array}{c}60^{\circ} \mathrm{C} / \\
16 \mathrm{~h}\end{array}$} \\
\hline & $\mathrm{J}$ & $\mathrm{NaCl}=2.0, \mathrm{NaF}=0.84$ & \\
\hline
\end{tabular}


inhibitor was weighed into the Erlenmeyer flask; in the second step, $50 \mathrm{~mL}$ of cation solution (e.g., brine A, C, E or $\mathrm{G})$ was added, shaked uniformly; and in the third step, $50 \mathrm{~mL}$ of anion solution (e.g., B, D, F, or H) was added, and then plugged by plastic stopper wrapped with polyethylene (PE) film. Wrap the entire flask by PE film, and then pack it tightly using Sellotape. Finally, the Erlenmeyer flasks were placed in the oven for predetermined time at a constant temperature (details in Table 1). For calcium fluoride test, similar procedure was adopted except that the polyethylene terephthalate (PET) bottles were used in place of Erlenmeyer flask for static evaluation test.

Inhibitor efficiency was calculated based on remaining $\mathrm{Ca}^{2+}, \mathrm{Ba}^{2+}$, and $\mathrm{Sr}^{2+}$ ions in solution according to the following equation.

Percentage inhibition $(\%)=\frac{m_{2}-m_{0}}{m_{1}-m_{0}} \times 100 \%$

Where $m_{2}$ was the mass concentration of $\mathrm{Ca}^{2+}, \mathrm{Ba}^{2+}$, or $\mathrm{Sr}^{2+}$ ions after inhibitor functions, $m_{1}$ was the mass concentration of $\mathrm{Ca}^{2+}, \mathrm{Ba}^{2+}$, or $\mathrm{Sr}^{2+}$ ions in the solution of which $50 \mathrm{~mL}$ deionized water without anions was added in the third step, $m_{0}$ was the mass concentration of $\mathrm{Ca}^{2+}$, $\mathrm{Ba}^{2+}$, or $\mathrm{Sr}^{2+}$ ions of the solution with no inhibitor. The test of the mass concentration of $\mathrm{Ca}^{2+}, \mathrm{Ba}^{2+}$, and $\mathrm{Sr}^{2+}$ ions was also followed the method specified by the standard TM0374-2007 and SY/T 5673-1993.

Effects on the inhibition performance of inhibitor

\section{Temperature}

As we know, the tendency of scale forming is affected by temperatures (Dyer and Graham 2002), and the polymeric inhibitor has different inhibition ability at different temperatures. Generally, the performance of inhibitor gets to be challenged at higher temperature. Thus, the inhibition performance of the inhibitor at 80 and $90{ }^{\circ} \mathrm{C}$ was also studied in this work.

\section{pH value}

With the variation of acid gas concentration (such as $\mathrm{CO}_{2}$, $\mathrm{H}_{2} \mathrm{~S}$ ), or being affected by adding demulsifiers, corrosion inhibitors and other agents, $\mathrm{pH}$ value of the oilfield formation water will be changed, as a result the scaling trend of the water changed as well. In oilfield production system, the $\mathrm{pH}$ value of the oilfield produced water is generally between 6.5 and 9.0. The $\mathrm{pH}$ values of 7.0, 7.4, 8.0, 8.4, and 9.0 were selected here to study the inhibition performance of the polymer on calcium carbonate and barium sulfate. The $\mathrm{pH}$ of the solution was adjusted by borax-boric acid buffer solution. The solutions for calcium carbonate evaluation were saturated with $\mathrm{CO}_{2}$ at room temperature after adjusting to the required $\mathrm{pH}$ value.

\section{Concentration of $\mathrm{NaCl}$}

High salinity is a significant feature of the oilfield water. It is primarily dominated by sodium chloride, potassium chloride and magnesium chloride, among which sodium chloride is accounting to more than $90 \%$ in most cases as we know. Salts have an obvious impact on the scaling tendency by affecting the ionic strength of the oilfield produced water, and influence the properties of the inhibitor. The inhibition properties of the copolymer at different sodium chloride concentration were investigated. For the calcium carbonate inhibition performance evaluation, the concentration of $\mathrm{NaCl}$ was 5.5, 11, 22, 33, 66 and $99 \mathrm{~g} / \mathrm{L}$, respectively. For evaluating the inhibition performance on barium sulfate, the concentration of $3.75,7.5,15,30$ and $60 \mathrm{~g} / \mathrm{L}$ was selected.

\section{Evaluation time}

Effective inhibition time is an important aspect for the evaluation of the performance of scale inhibitor, it is necessary to study the inhibition performance of inhibitor along with the time. That will determine the squeezing or injecting method of inhibitor (continuous or intermittent). Through the research of the effective time of the scale inhibitor, we can have a better understanding on the inhibition function. Different heat time from 8 to $72 \mathrm{~h}$ was chosen to evaluate the performance of the scale inhibitor.

\section{XRD and SEM characterization}

The calcium carbonate, barium sulfate, and strontium sulfate deposition were obtained at low/no inhibitor dosage; they were carefully collected and dried for characterization. The X-ray diffraction (XRD, CAD-SDPMH, Netherlands Enraf-Nonius) was used to study the crystal structure of the scale. The scanning electron microscope (SEM, HITACHI S-4800, Japan) was used to observe the surface morphology of the scale crystal.

The inhibition performance of the inhibitor in oilfield water

The water-cut crude oil was from an oilfield of Northwest area in China. Test brines (produced water) were obtained through chemical demulsification/high-speed centrifugal and membrane filtering. Table 2 shows the concentration of compositions in the produced water. The following evaluation conditions are listed as below: heated at $60{ }^{\circ} \mathrm{C}$ for $24 \mathrm{~h}$ without carbon dioxide as test 1 ; heated at $60{ }^{\circ} \mathrm{C}$ 
Table 2 Composition of oilfield produced water $(\mathrm{mg} / \mathrm{L})$

\begin{tabular}{lllllllllllll}
\hline No. & $\mathrm{pH}$ & $\mathrm{K}^{+}$ & \multicolumn{1}{c}{$\mathrm{Na}^{+}$} & $\mathrm{Ca}^{2+}$ & $\mathrm{Mg}^{2+}$ & $\mathrm{Ba}^{2+}$ & $\mathrm{Sr}^{2+}$ & $\mathrm{CO}_{3}^{2-}$ & $\mathrm{HCO}_{3}^{-}$ & $\mathrm{SO}_{4}^{2-}$ & $\mathrm{Cl}^{-}$ & $\sum \mathrm{Fe}^{2-}$ \\
\hline Solution 1 & 7.05 & 58.19 & 7,178 & 721.8 & 94.05 & 0.08 & 51.59 & 0 & 716 & 4,077 & 10,400 & 0.99 \\
Solution 2 & 8.01 & 78.61 & 11,190 & 213.5 & 99.02 & 0.01 & 11.67 & 0 & 1,319 & 8,680 & 14,000 & 0 \\
\hline
\end{tabular}

for $24 \mathrm{~h}$, and then heated at $70{ }^{\circ} \mathrm{C}$ for $24 \mathrm{~h}$ without carbon dioxide as test 2 ; the evaluation experiments for produced water with saturated carbon dioxide heated at $60{ }^{\circ} \mathrm{C}$ for $24 \mathrm{~h}$ and then heated at $70{ }^{\circ} \mathrm{C}$ for $24 \mathrm{~h}$ were done as test 3 . These tests were undertaken to simulate the actual situation of oilfield treatment as much as possible. The measurement of the inhibition performance of the as-prepared inhibitor was referred to the method specified by the standard TM0374-2007 and SY/T 5673-1993.

\section{Results and discussion}

\section{Characterization of copolymer}

The FT-IR spectra presented in Fig. 1 were used for confirming the structure of copolymer. The possible carboxylic group $(\mathrm{O}-\mathrm{H})$ or amine hydrogen $(\mathrm{N}-\mathrm{H})$ in the polymer is indicated by the peak at $3,430 \mathrm{~cm}^{-1}$. The peak at $1,660 \mathrm{~cm}^{-1}$ represents the characteristic absorption of $\mathrm{C}=\mathrm{O}$ of primary amide. The peaks at 1,580 and $1,402 \mathrm{~cm}^{-1}$ represent the $\mathrm{C}=\mathrm{O}$ and band of $\mathrm{C}-\mathrm{O}$ stretching vibration of -COONa (Su et al. 2002), and $1,402 \mathrm{~cm}^{-1}$ also represents the combination of $\mathrm{C}-\mathrm{O}$ stretching vibration and $\mathrm{O}-\mathrm{H}$ in plane deformation (Senthilmurugan et al. 2010). The peaks at 1,320 and $1,130 \mathrm{~cm}^{-1}$ represent the asymmetric and symmetric stretching vibrations of $\mathrm{C}-\mathrm{O}-\mathrm{C}$ in ester group. At peak of $1,050 \mathrm{~cm}^{-1},-\mathrm{OH}$ in primary alcohol and $\mathrm{S}=\mathrm{O}$

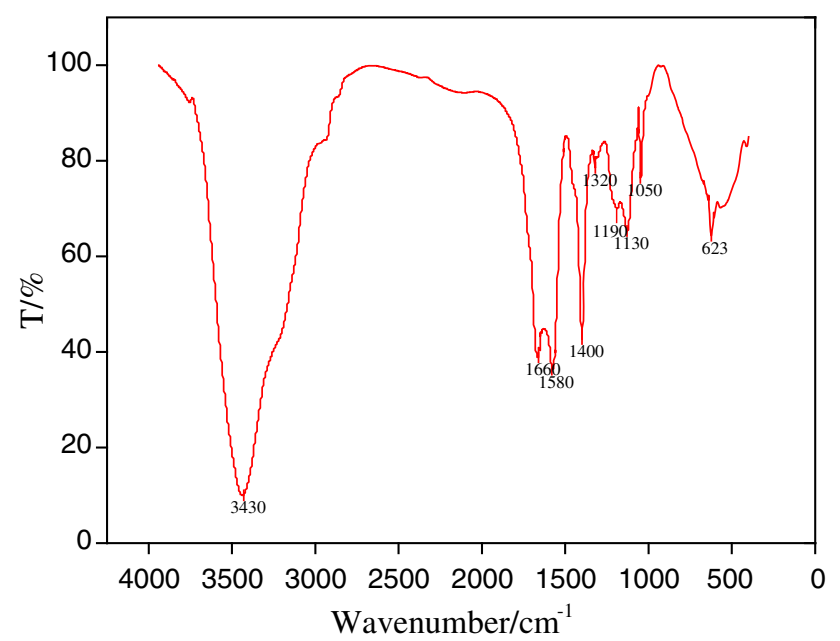

Fig. 1 FT-IR spectrum of the polymer

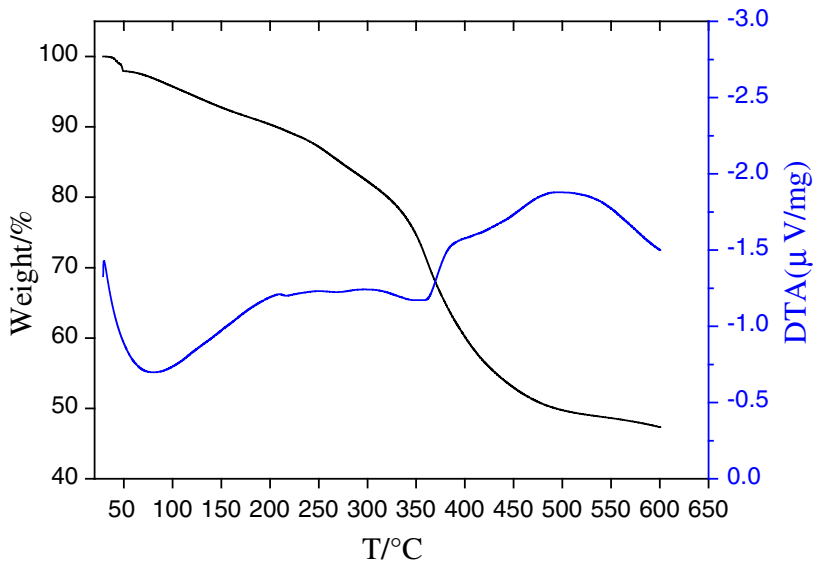

Fig. 2 TG spectrum of the polymer

stretching vibration can be found. All these facts confirm the structure of the expected copolymer. The functional groups were responsible for the scale inhibition properties, the inhibition ability of the polymer could be revealed.

The TG-DTA spectrum in Fig. 2 indicates that less than $15 \%$ weight loss occurred at $270{ }^{\circ} \mathrm{C}$, revealed that the polymer presents a good thermal stability. The heat absorption peak existed lower than $100{ }^{\circ} \mathrm{C}$ as can be seen from the DTA spectrum may caused by the evaporation of residual water. The DTA curve keeps relative smooth between 150 and $300{ }^{\circ} \mathrm{C}$ revealed that the polymer possesses favorable stability. The initial decomposition temperature of the polymer is about $330{ }^{\circ} \mathrm{C}$ through the DTA analysis and TG curve fitting. It is reasonably concluded that the polymer possesses a well anti-temperature capability.

Evaluation of scale inhibition performance

Figure 3 shows the inhibition performance (at $70^{\circ} \mathrm{C}$ ) of the polymer on calcium sulfate (Fig. 3a), calcium carbonate (Fig. 3b), strontium sulfate (Fig. 3c), barium sulfate (Fig. 3d) with the dosage of copolymer. As can be seen from the figures, with the increase of the inhibitor dosage, the inhibition efficiency increased, when the dosage reaches a critical value, the inhibition rate is highest which is higher than $95 \%$, after that the inhibition rate exhibited a plateau or a slight decrease tendency. For calcium sulfate, the inhibitor exhibited high inhibition efficiency at a low dosage of $1.25 \mathrm{mg} / \mathrm{L}$ (ppm), the best inhibition efficiency of $97 \%$ can be obtained at dosage of 5 ppm. For the 

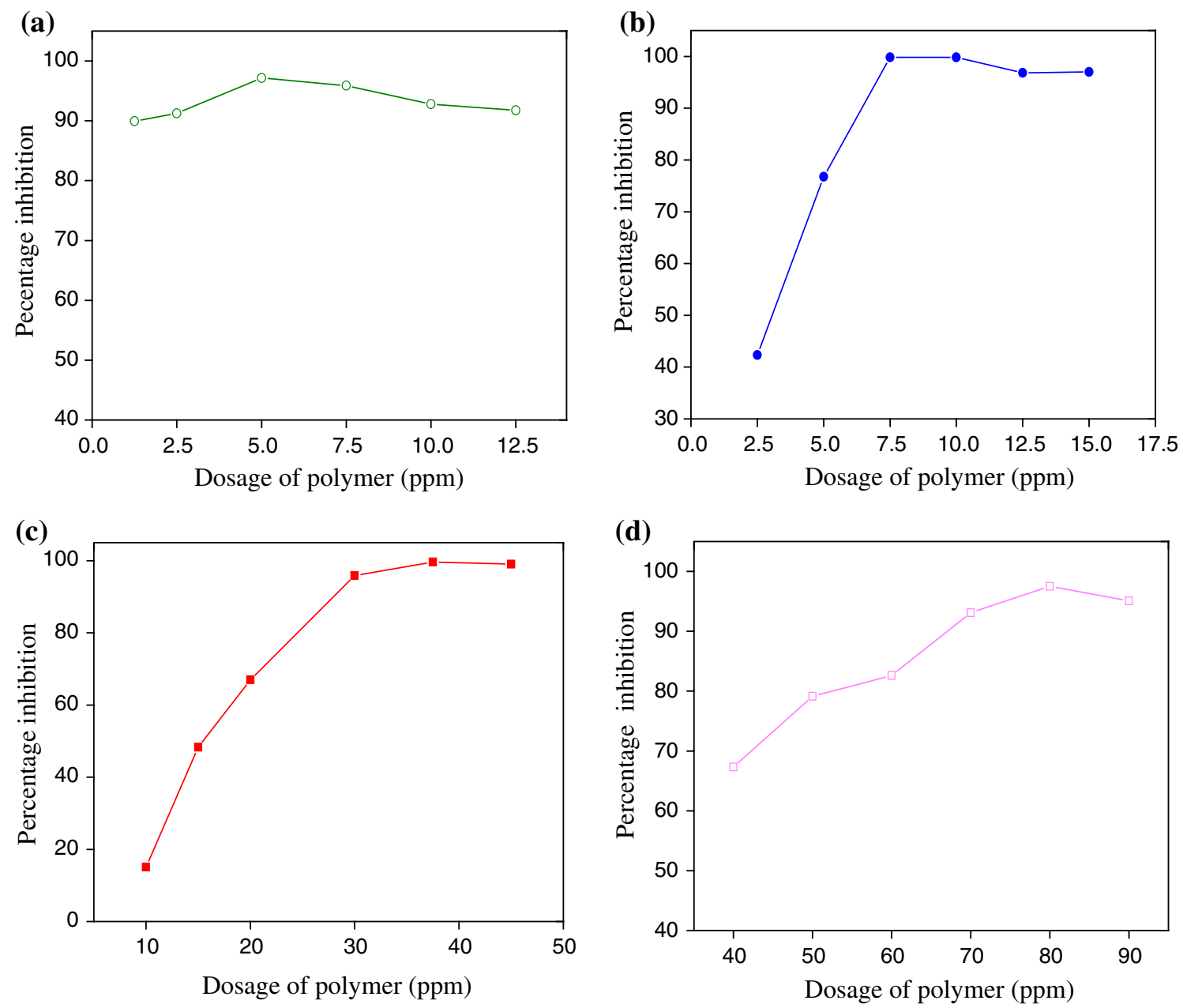

Fig. 3 Relation curve of dosage to inhibition efficiency $\left(70^{\circ} \mathrm{C}\right)$ on a calcium sulfate, $\mathbf{b}$ calcium carbonate, $\mathbf{c}$ barium sulfate, $\mathbf{d}$ strontium sulfate

calcium carbonate inhibition performance evaluation, the inhibition rate increased sharply higher than $50 \%$ with the antiscalant dosage increased from 2.5 to $7.5 \mathrm{ppm}$. At the optimum dosage of $7.5 \mathrm{ppm}$, a inhibition efficiency of $99 \%$ on calcium carbonate can be obtained. It can be seen from Fig. 3 that the optimum inhibitor dosage for barium sulfate is $40 \mathrm{ppm}$ (inhibition efficiency of $99 \%$ ), for strontium sulfate is $80 \mathrm{ppm}$ (inhibition efficiency of $97.5 \%)$ under the evaluations. It is clearly demonstrated that the polymer exhibits a relatively good inhibition performance on calcium sulfate, calcium carbonate, strontium sulfate, and barium sulfate.

Figure 4 shows the inhibition rate of the polymer on calcium fluoride. At dosage lower than $100 \mathrm{ppm}$, very low inhibition rate can be observed, the inhibition rate increases with further addition of the polymer inhibitor. The opaque suspension occurred between 150 and $300 \mathrm{ppm}$ inhibitor dosage, which means calcium fluoride was dispersed at the solution. The inhibition rate on calcium fluoride became $94 \%$ at the inhibitor dosage of

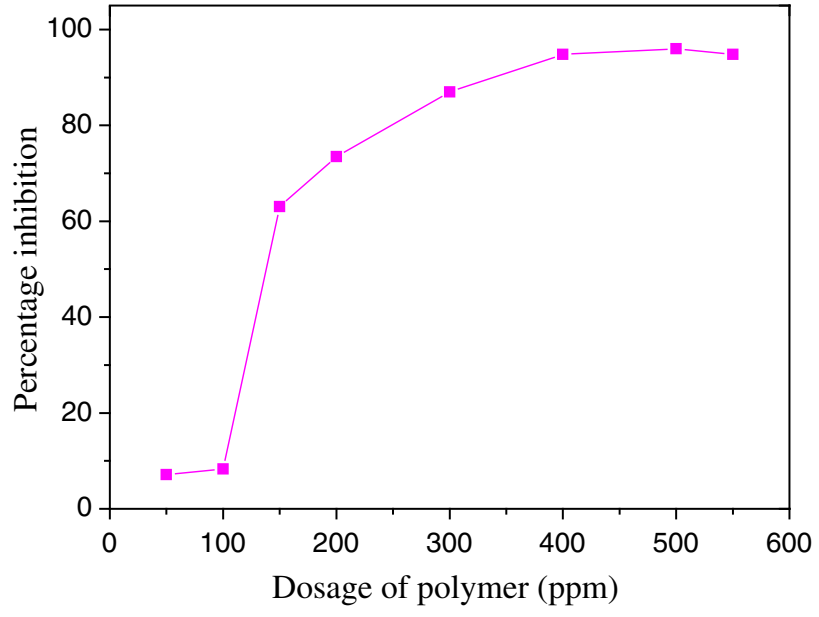

Fig. 4 Inhibition performance $\left(70{ }^{\circ} \mathrm{C}\right)$ of the polymer on calcium fluoride

$400 \mathrm{ppm}$. Undoubtedly, the dosage is extremely high, so further study on dispersant and inhibitor on calcium fluoride is needed. 

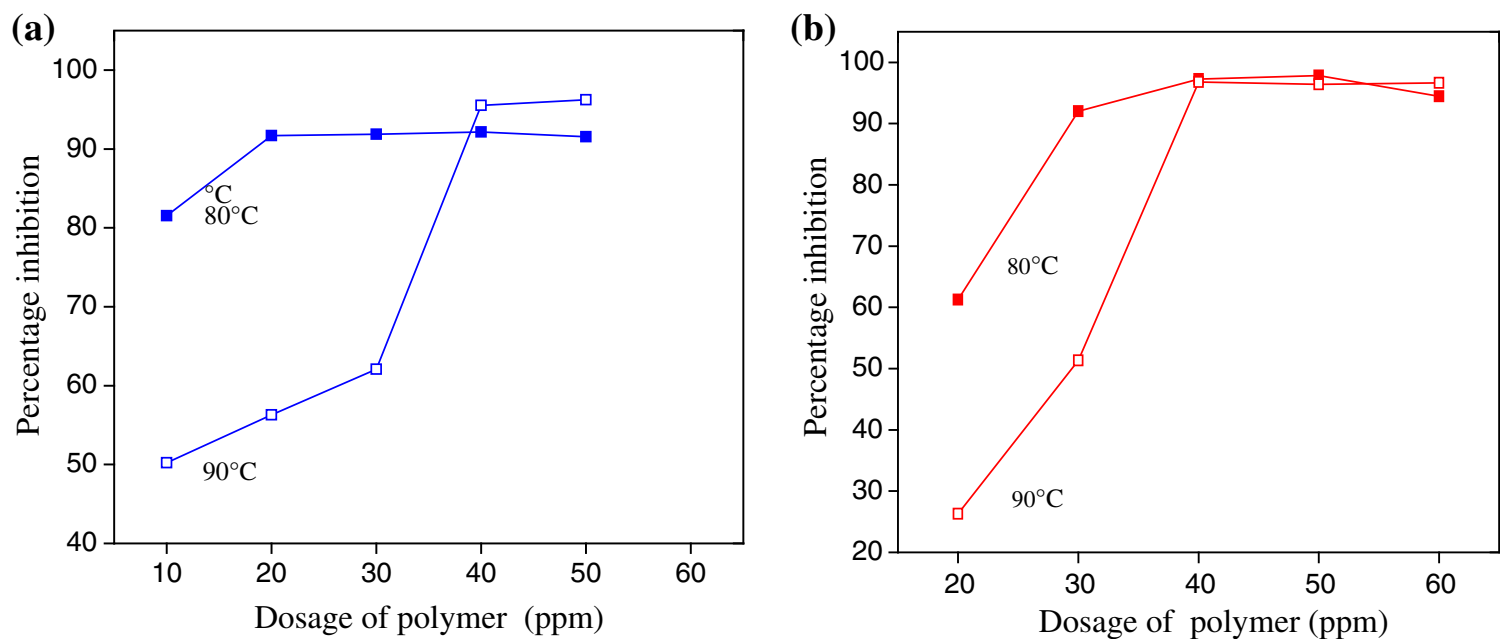

Fig. 5 Effect of temperature on the inhibition efficiency on a calcium carbonate (inhibitor dosage of $10 \mathrm{ppm}$ ), b barium sulfate (inhibitor dosage of $40 \mathrm{ppm})$

Effects on the inhibition performance of the antiscalant

\section{Temperature}

As can be seen from the Fig. 5a, the scale inhibition efficiency on calcium carbonate achieves higher than $90 \%$ with the dosage of $20 \mathrm{ppm}$ at $80{ }^{\circ} \mathrm{C}$ while a dosage of $40 \mathrm{ppm}$ is needed for $90{ }^{\circ} \mathrm{C}$. This may be attributed to the fact that the high temperature makes the calcium carbonate easy to form, as a result, the additional antiscalant dosage is necessary to get better efficiency. When the dosage added up to a certain value (40 ppm), the inhibition rate at $90{ }^{\circ} \mathrm{C}$ is higher than $80{ }^{\circ} \mathrm{C}$, the fact that more polymer adsorption on the calcium carbonate crystal nuclei at higher temperature may account for this phenomenon. For inhibition property on barium sulfate (Fig. 5b), when the optimal dosage at $70{ }^{\circ} \mathrm{C}(40 \mathrm{ppm})$ was added, the nearly identical inhibition rate $(96 \%)$ can be obtained at 80 and $90^{\circ} \mathrm{C}$. On the whole, at higher temperatures, extra inhibitor dosage is needed to maintain a high inhibition rate for calcium carbonate control, while no further dosage is required for barium sulfate in the scope of this work.

\section{Concentration of $\mathrm{NaCl}$}

Figure 6 shows the effect of the concentration of sodium chloride on the inhibition efficiency of the polymer. Scale inhibition rate is increasing with the increase of the $\mathrm{NaCl}$ content, the inhibition rate on calcium carbonate rises dramatically when the concentration is higher than $11 \mathrm{~g} / \mathrm{L}$, the inhibition rate reached more than $95 \%$ as the $\mathrm{NaCl}$ concentration higher to $99 \mathrm{~g} / \mathrm{L}$. At the $\mathrm{NaCl}$ concentration of $3.75 \mathrm{~g} / \mathrm{L}$, the scale inhibitor possessed poor performance for barium sulfate inhibition, and at the salt content of $7.5 \mathrm{~g} / \mathrm{L}$ or more, the scale inhibition rate was more than $90 \%$. And the scale inhibition rate on barium sulfate is better at the higher concentration of $\mathrm{NaCl}$. Therefore, the scale inhibitor with high concentration of $\mathrm{NaCl}$, i.e., higher than $7.5 \mathrm{~g} / \mathrm{L}$, is more suitable for the scale inhibition.

\section{pH value}

Figure 7 shows the effect of $\mathrm{pH}$ value on the scale inhibitor performance. When the $\mathrm{pH}$ is lower than 8.5 , the scale inhibitor presented a good ability on calcium carbonate, there is a slight decrease when the $\mathrm{pH}$ is higher than 8.5 (i.e., 9.0). The reason may be due to that the high concentration of hydroxyl at $\mathrm{pH}$ value of 9 , reacted easily with bicarbonate ions and transformed to a large amount of carbonate ions (more than $2,600 \mathrm{mg} / \mathrm{L}$ ) which generated calcium carbonate at identical dosage of antiscalant, so more scale precipitation appeared. For barium sulfate, it can be concluded that the better scale inhibition is shown at the higher $\mathrm{pH}$ though the scale inhibition rate of $\mathrm{pH}=9.0$ is slightly lower than that of 8.4. It should be attributed that the carboxyl group on the polymeric inhibitor has a stronger ionization and higher electrostatic repulsion at the higher $\mathrm{pH}$ value.

\section{Time}

Effect of inhibition time on the evaluation of the performance of scale inhibitor is shown in Fig. 8. As shown in Fig. 8a, the inhibition efficiency on calcium carbonate at an evaluation time of $72 \mathrm{~h}$ still has a high inhibition rate higher than $95 \%$, which indicates that the polymer plays a continuous calcium carbonate inhibition performance. For 

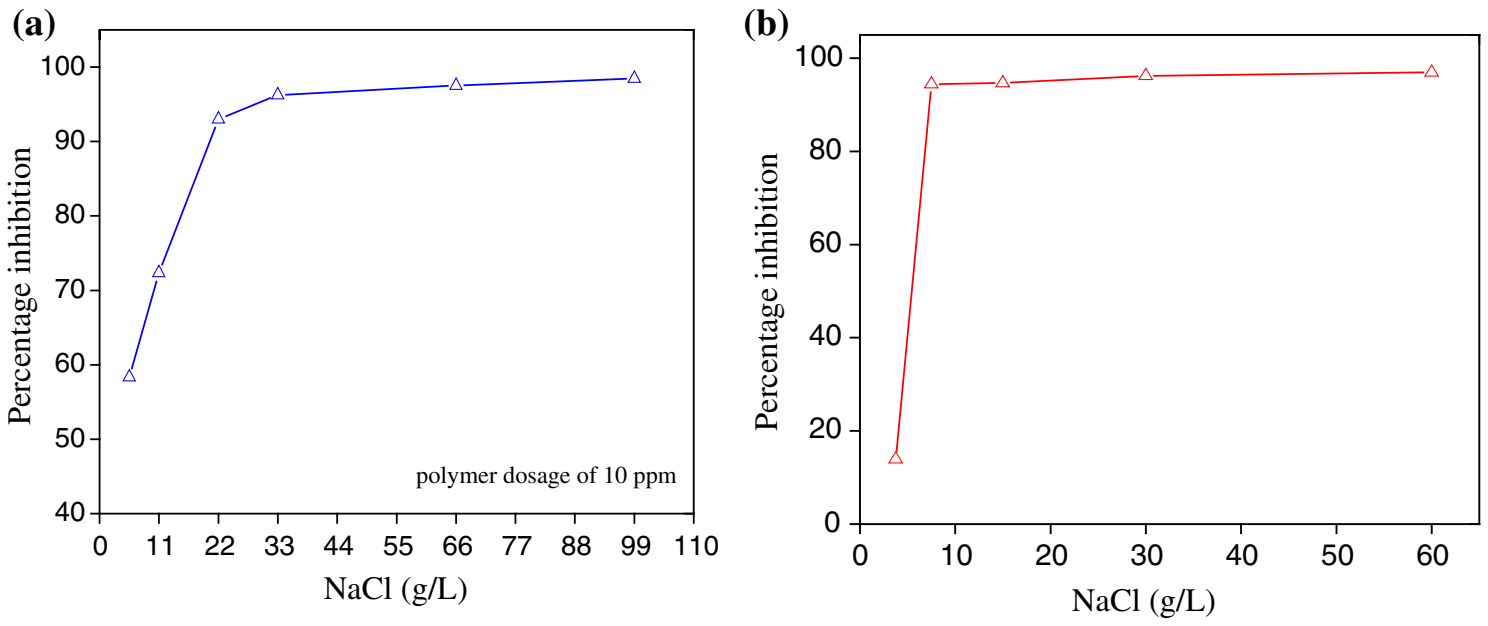

Fig. 6 Effect of concentration of $\mathrm{NaCl}$ on the inhibition efficiency on a calcium carbonate (inhibitor dosage of $10 \mathrm{ppm}$ ), b barium sulfate (inhibitor dosage of $40 \mathrm{ppm}$ )
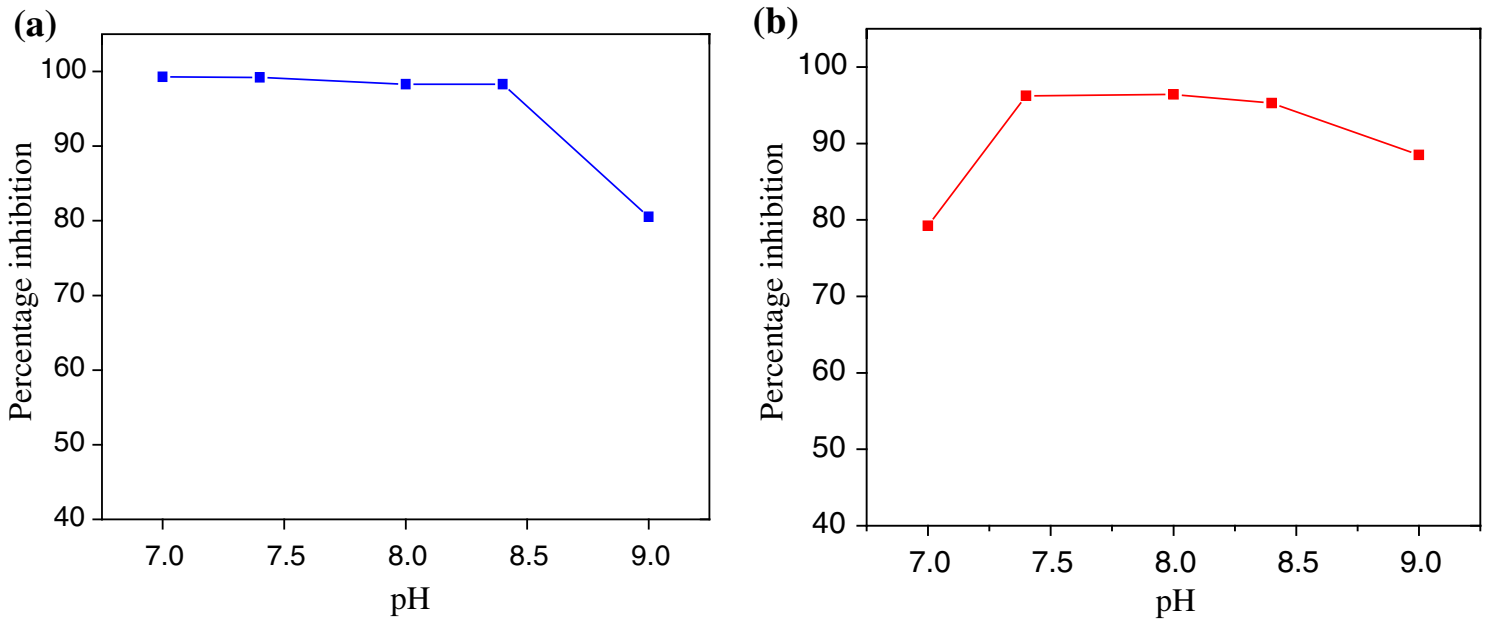

Fig. 7 Effect of $\mathrm{pH}$ value on the inhibition efficiency on a calcium carbonate (inhibitor dosage of $10 \mathrm{ppm}$ ), $\mathbf{b}$ barium sulfate (inhibitor dosage of $30 \mathrm{ppm})$
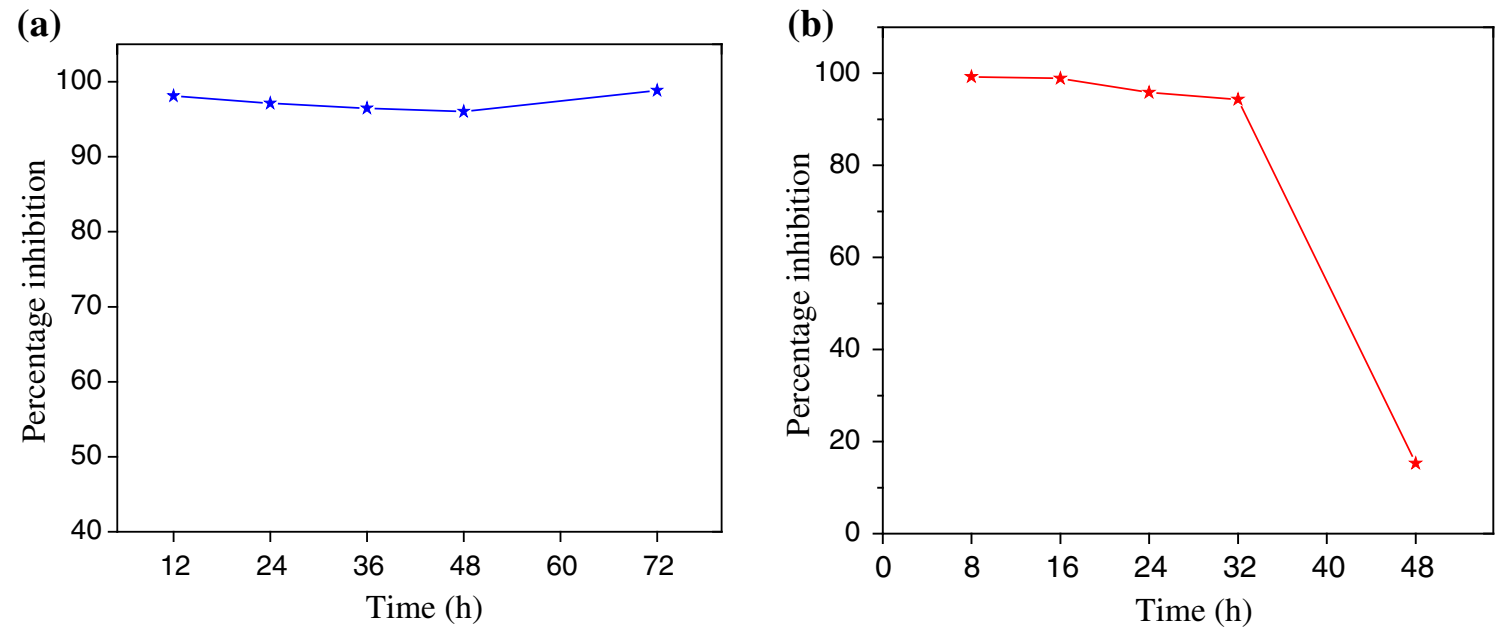

Fig. 8 Effect of evaluation time on the inhibition rate on a calcium carbonate (inhibitor dosage of $10 \mathrm{ppm}$ ), b barium sulfate (inhibitor dosage of $40 \mathrm{ppm})$ 
barium sulfate deposition inhibition experiments (Fig. 8b), the scale inhibition rate is apparently decreased after $36 \mathrm{~h}$ at $70{ }^{\circ} \mathrm{C}$. The reason may be that the combination of polymeric scale inhibitor with barium ions or fine crystal of barium sulfate is weak. The combination process was an adsorption-desorption equilibrium, larger extent of desorption could occur for longer time evaluation at a constant temperature which may lead to a reduced scale inhibition efficiency. So, it is necessary to assure a sufficient dosage for controlling the barium sulfate in long time. The method of continuous injecting of inhibitor is probably another route for improving the inhibition efficiency with the constant inhibitor dosage.

(A)
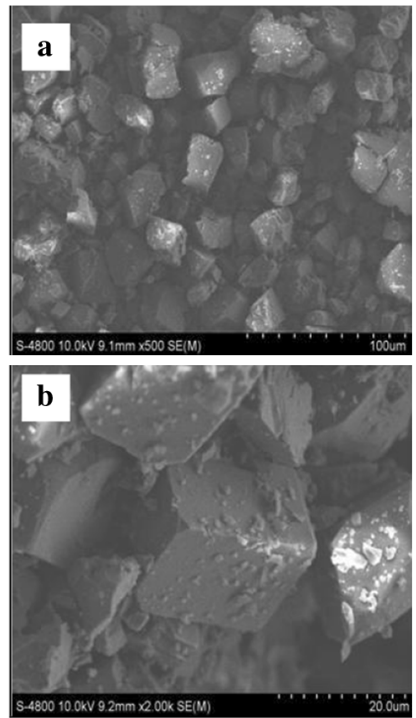

(C)
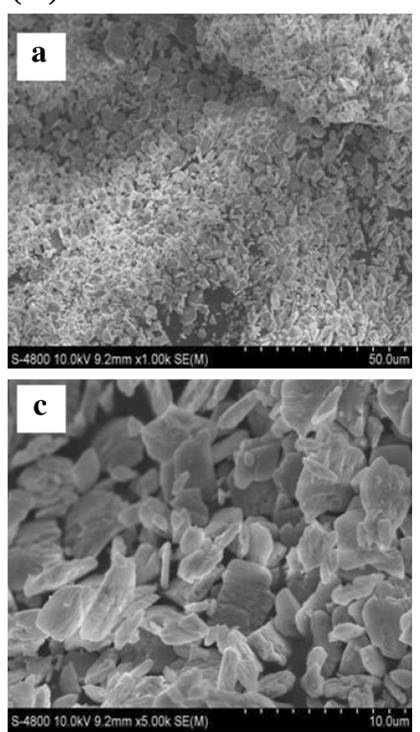
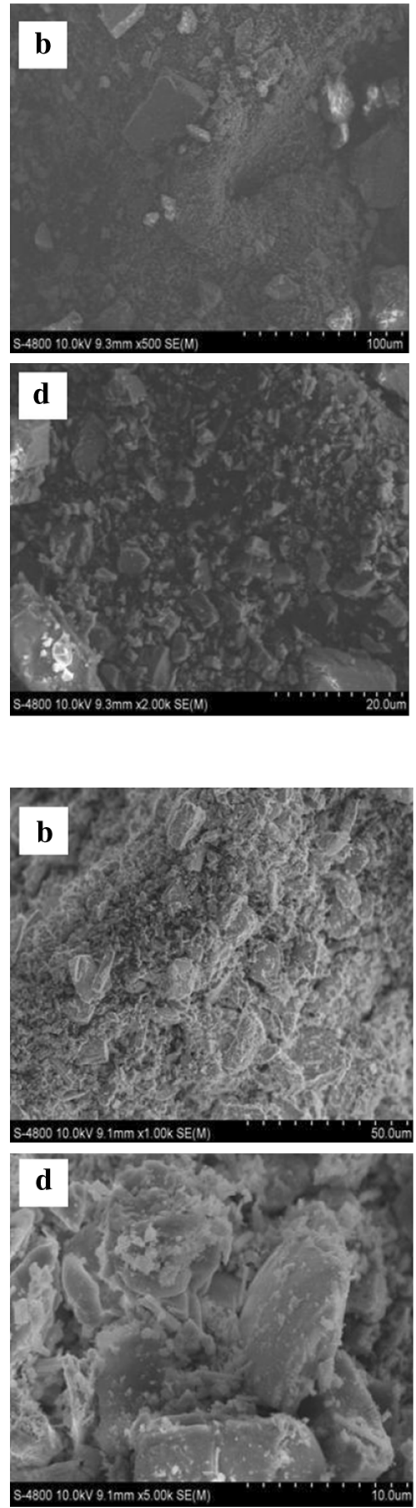

XRD and SEM analyses

XRD patterns and SEM images of calcium carbonate, barium sulfate, strontium sulfate obtained from the absence or low dosage of inhibitor shown in Figs. 9 and 10, respectively. The crystal of calcium carbonate in the absence of carbon dioxide showed a cube shape (Fig. 9A-a, Fig. 9A-c), but there were many non-cube shaped particles under the presence of carbon dioxide, (Fig. 9A-b, Fig. 9Ad). Therefore, lattice distortion caused by scale inhibitor may play a weak role for calcium carbonate scale inhibition in the oilfield environment containing carbon dioxide. However, the scale inhibition mechanism may include the

(B)
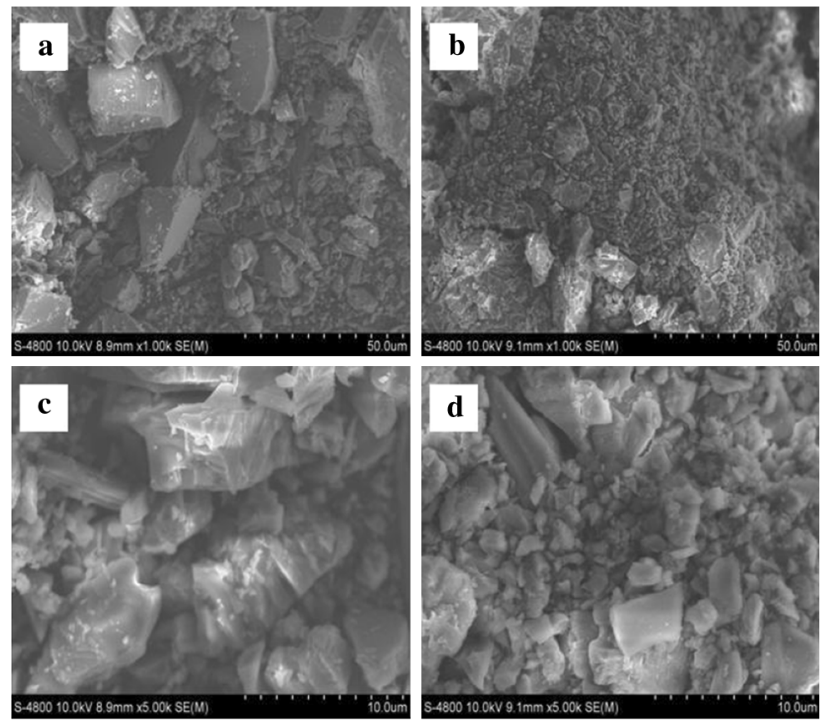

(D)
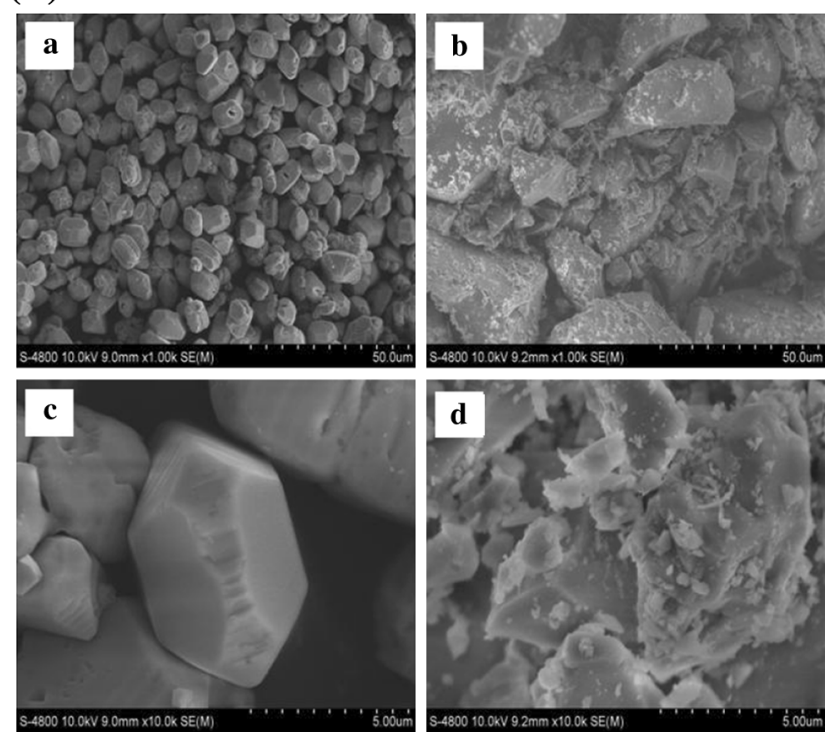

Fig. 9 SEM images of $\mathbf{A}$ were $\mathrm{CaCO}_{3}$ without $(a, c)$ and with $\mathrm{CO}_{2}(b, d)$, $\mathbf{B}$ were $\mathrm{CaCO}_{3}$ (saturated with $\left.\mathrm{CO}_{2}\right)$ without $(a, c)$ and with inhibitor $(b, d), \mathbf{C}$ were $\mathrm{BaSO}_{4}$ without $(a, c)$ and with inhibitor $(b, d)$, $\mathbf{D}$ were $\mathrm{SrSO}_{4}$ without $(a, c)$ and with inhibitor $(b, d)$ 

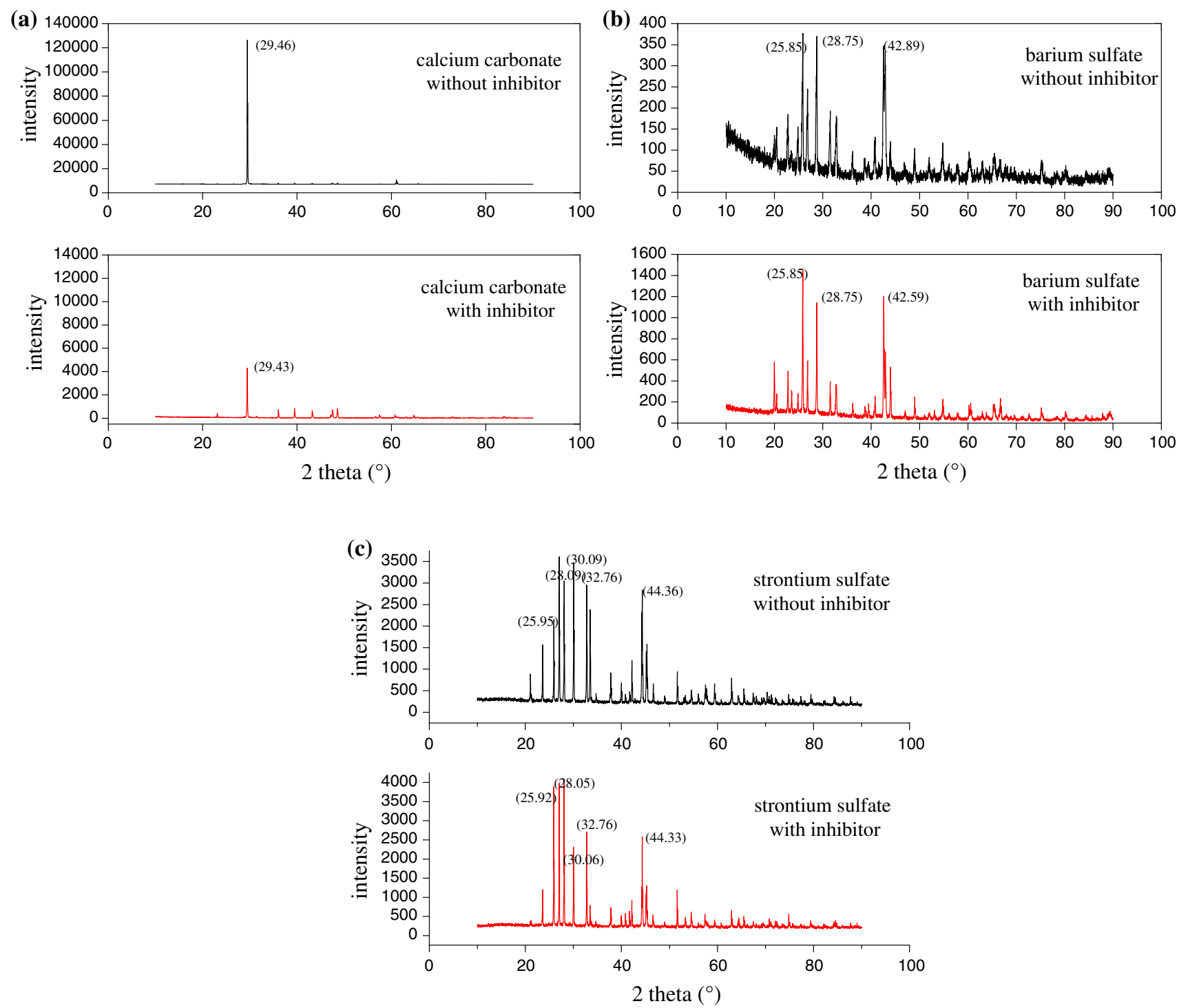

Fig. 10 XRD patterns of a calcium carbonate, $\mathbf{b}$ barium sulfate, $\mathbf{c}$ strontium sulfate scale

Table 3 Mass of scale deposition generated in oilfield produced water absence of inhibitor after heating

\begin{tabular}{lll}
\hline No. & Solution $1(\mathrm{mg} / \mathrm{L})$ & Solution $2(\mathrm{mg} / \mathrm{L})$ \\
\hline Test 1 & 297 & 383 \\
Test 2 & 385 & 571 \\
Test 3 & Nearly 0 & Nearly 0 \\
\hline
\end{tabular}

lattice distortion in the less/none-carbon dioxide system as many researches stated before. SEM graphs (Fig. 9B) and XRD patterns (Fig. 10a) of the calcium carbonate deposition (carbon dioxide condition) without and with synthesized polymer reveal that the added inhibitor lead to more amounts of the fine-size particles (Fig. 9B-b, d). The XRD peak intensity reduced significantly with the presence of synthesized polymer (Fig. 10a) shows that the preferential growth of crystals of calcium carbonate was strongly inhibited.

For barium sulfate, the rule dense-flake crystals changed to be loose, irregular polyhedron (Fig. 9c) which indicates that the crystals were suppressed. For strontium sulfate (Fig. 9d), similar phenomenon was observed, the rule polyhedral cone changed to loose taper lump. The loose material could be easily disturbed by fluid turbulence and suspended in the solution (Shen et al. 2012). It is also worth mentioning that the diameter of crystal of barium sulfate and strontium sulfate is larger with the presence of inhibitor, so the visual inhibition efficiency may be not intuitively dropped. This may be attributed that the polymer has some influence to surface phase of the barium sulfate and strontium sulfate crystal (Mavredaki et al. 2011). 

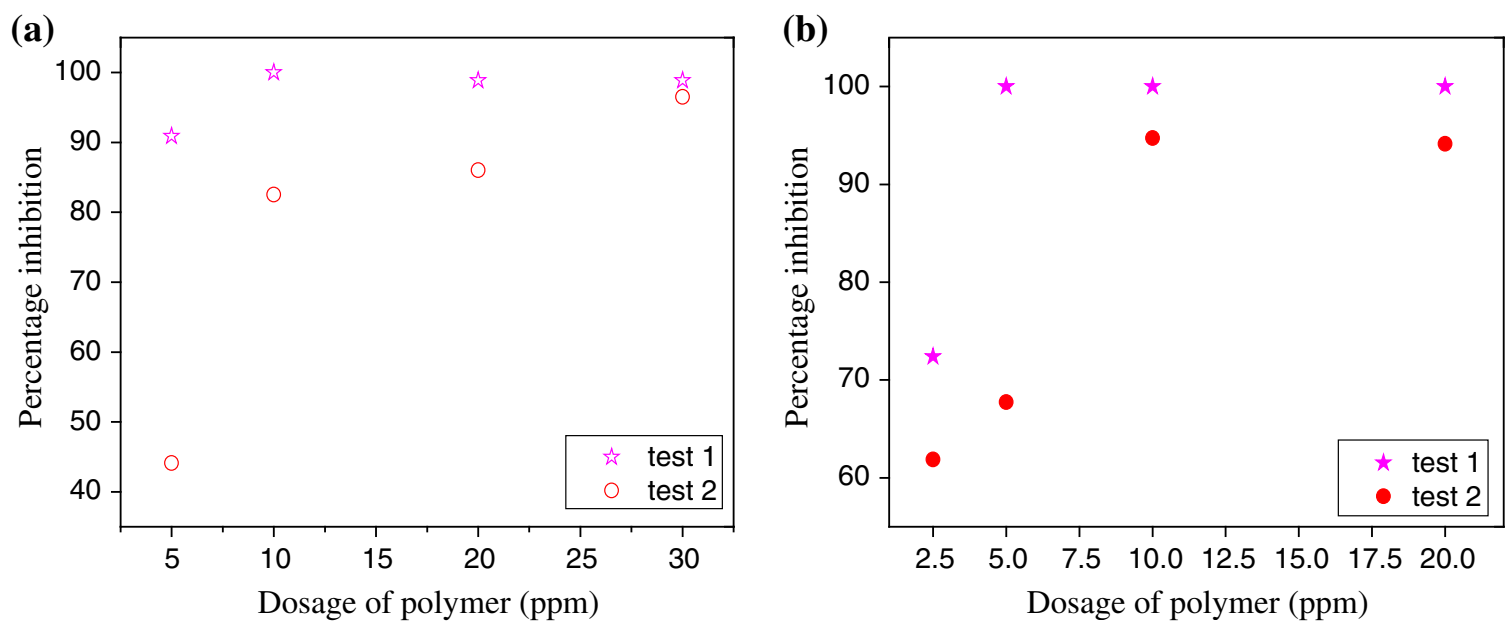

Fig. 11 Inhibition efficiency of the polymer at the actual oilfield water a Solution 1 and b Solution 2

Therefore, maintaining a sufficient amount of scale inhibitor for prevention of the formation of barium sulfate and strontium sulfate is necessarily required. From XRD patterns (Fig. 10b, c), peak intensity and the peak position of the barium sulfate and strontium sulfate with the absence or presence of inhibitor are not changed distinctively, that is, the addition of inhibitor did not alter the crystal structure (Shakkthivel and Vasudevan 2007). It could be found that ' $2 \theta$ ' values are not exactly same as Fig. 10 shown, indicating some degree of difference in crystal morphology between inhibited and uninhibited crystals (Senthilmurugan et al. 2010) which were also observed by SEM.

Inhibition performance of the polymer in actual oilfield water

The mass weight of scale deposition (calculated by calcium carbonate hardness) generated at Solution 1 and Solution 2 with the absence of inhibitor in test 1 , test 2 and test 3 is shown in Table 3. The evaluation results of the inhibitor in actual produced water as shown in Fig. 11. The inhibitor possessed a good performance in Solution 1 after $60^{\circ} \mathrm{C} / 24 \mathrm{~h}$ and then $70^{\circ} \mathrm{C} / 24 \mathrm{~h}$ heating at the dosage of $30 \mathrm{ppm}$. The inhibition efficiency in test 2 was lower than test 1 which may be caused by the existed crystal formed at $60{ }^{\circ} \mathrm{C}$ continued to grow when the thermodynamic condition changed $\left(70{ }^{\circ} \mathrm{C}\right)$. So increasing temperature makes the scale forming more serious in actual oilfield water, and a stable thermodynamic environment is beneficial to scale prevention. In addition in test 3 , nearly no scales were generated in Solution 1 and Solution 2 without or with scale inhibitor, owing to the Solutions having no/low scale tendency in the saturated carbon dioxide condition while the concentration of scaleforming ions was also low, revealing that scale control is easier in the carbon dioxide environment if corrosion is neglected.

\section{Conclusions}

1. A potential copolymer scale inhibitor for oilfield was prepared, and its inhibition performance on calcium carbonate, calcium sulfate, barium sulfate, and strontium sulfate was evaluated, and the inhibition efficiency could achieve higher than $95 \%$. The inhibition rate on calcium fluoride could achieve higher than $94 \%$, however, the dosage is required extremely high, so further attempts are needed for the inhibitor on calcium fluoride.

2. It is found that extra amount of antiscalant is necessary for achieving well-inhibition performance on calcium carbonate deposition at higher temperature and higher $\mathrm{pH}$, while for the barium sulfate scale inhibition it is not necessary.

3. Sodium chloride concentration affects the inhibition performance of the polymer on calcium carbonate and barium sulfate, but the polymer can play a good ability in the high $\mathrm{NaCl}$ content environment. The synthesized polymer reveals an excellent inhibition performance on calcium carbonate after heating for $72 \mathrm{~h}$ while the inhibition efficiency of the polymer on barium sulfate shows a sharp degradation along with the evaluation time.

4. The diameter of barium sulfate and strontium sulfate formed at low dosage of inhibitor is larger than the ones under blank conditions, thus adequate dosage for the prevention for barium sulfate and strontium sulfate is extremely important.

5. It is also found that carbon dioxide has lattice distortion effect on the crystal of calcium carbonate.

Acknowledgments This work was financially supported by the Funds for Creative Research Groups of China (Grant No. 51121062) and Excellent Young Teachers in Lanzhou University of Technology Training Project (Grant No. 1005ZCX016). 
Open Access This article is distributed under the terms of the Creative Commons Attribution License which permits any use, distribution, and reproduction in any medium, provided the original author(s) and the source are credited.

\section{References}

Dickinson W, Sanders L, Kemira (2012) Novel barium sulfate scale inhibitor for use in high iron environments. SPE Latin American and Caribbean Petroleum Engineering Conference, Mexico City, Mexico, April 16-18 2012

Dickson W, Griffin R, Sanders L, Lowen C, Kemira (2011) Development and performance of biodegradable antiscalants for oilfield applications. In: Offshore Technology Conference, Houston, USA, 2-5 May 2011

Dyer SJ, Graham GM (2002) The effect of temperature and pressure on oilfield scale formation. J Petrol Sci Eng 35:95-107

El-Said M, Ramzi M, Abdel-Moghny T (2009) Analysis of oilfield waters by ion chromatography to determine the composition of scale deposition. Desalination 249:748-756

Guo XR, Qiu FX, Dong K, Zhou X, Qi J, Zhou Y, Yang DY (2012) Preparation, characterization and scale performance of scale inhibitor copolymer modification with chitosan. J Ind Eng Chem 18:2177-2183

Jensen MK, Kelland MA (2012) A new class of hyperbranched polymeric scale inhibitors. J Petrol Sci Eng 94-95:66-72

Liu X, Chen T, Chen P, Montgomerie H, Hagen T, Wang B, Yang X (2012) Understanding the co-deposition of calcium sulphate and barium sulphate and developing environmental acceptable scale inhibitors applied in HTHP wells. SPE international conference and exhibition on oilfield Scale, Aberdeen, UK, 30-31 May 2012

Mavredaki E, Neville A, Sorbie KS (2011) Initial Stages of Barium Sulfate Formation at Surfaces in the Presence of Inhibitors. Cryst Growth Des 11:4751-4758

Senthilmurugan B, Ghosh B, Kundu SS, Haroun M, Kameshwari B (2010) Maleic acid based scale inhibitors for calcium sulfate scale inhibition in high temperature application. J Petrol Sci Eng 75:189-195

Senthilmurugan B, Ghosh B, Sanker S (2011) High performance maleic acid based on oil well scale inhibitors-development and comparative evaluation. J Ind Eng Chem 17:415-420

Shakkthivel P, Vasudevan T (2007) Newly developed itaconic acid copolymers for gypsum and calcium carbonate scale control. J Appl Polym Sci 103:3026-3213

Shen ZH, Li JS, Xu K, Ding LL, Ren HQ (2012) The effect of synthesized hydrolyzed polymaleic anhydride (HPMA) on the crystal of calcium carbonate. Desalination 284:238-244

Shen XZ, Zhao RM, Gu HF (2013) Analysis of calcium fluoride scaling and treatment measures. Metall Power 4:67-70 (in Chinese)

Su KM, Pan TY, Zhang YL (2002) Methods of spectral analysis. East China University of Science and Technology Press, Shanghai, pp 102-103

Zhang YX, Wu JH, Hao SC, Liu MH (2007) Synthesis and inhibition efficiency of a novel quadripolymer inhibitor. Chin J Chem Eng 15:600-605 